DOI: http://dx.doi.org/10.18764/2358-4319.v10n2p185-204

\title{
A carreira docente nos Institutos Federais em comparação com outras escolas públicas
}

João Leandro Cássio de Oliveira ${ }^{1}$

Claudio Pinto Nunes ${ }^{2}$

\section{RESUMO}

A pesquisa tem como objeto de estudo o trabalho e o plano de carreira dos docentes dos Institutos Federais no Brasil (IFs). A partir da análise comparativa com a realidade docente nacional, objetiva-se refletir sobre as condições do trabalho docente em uma entidade com menos de uma década de existência no país. Como orientação metodológica, realizouse uma pesquisa descritiva de caráter documental e bibliográfico, nos permitindo alcançar o objetivo proposto. Na sistematização das informações apuradas, foi demonstrado que os docentes dos IFs são estimulados à qualificação (mestrado e doutorado), dispõem de laboratórios, de estruturas para pesquisa e extensão, de cargas horárias de trabalho flexíveis que permitem a eles prepararem suas aulas e terem a vida pessoal tranquila, diferentemente dos professores das redes públicas municipal e estadual.

Palavras-chave: Carreira Docente. Formação Docente. Institutos Federais. Condições de trabalho.

\section{Teaching career in Federal Institutes in comparison to other public schools}

\section{ABSTRACT}

This research aims to study the teachers' work and career plan at Federal Institutes in Brazil (IFs). From the comparative study based on

1 Mestre em Educação pela Universidade Estadual do Sudoeste da Bahia (UESB). Doutorando em Inovação (UFMG). Professor do Instituto Federal do Norte de Minas Gerais (IFNMG). Membro do Grupo de Estudos e Pesquisa sobre Didática, Formação e Trabalho Docente (Difort).E-mail: jlc.oliveira@yahoo.com.br;

2 Doutor em Educação pela Universidade Federal do Rio Grande do Norte (UFRN). Professor Titular da Universidade Estadual do Sudoeste da Bahia (UESB) e do Programa de PósGraduação em Educação da mesma universidade. Líder do Grupo de Estudos e Pesquisa sobre Didática, Formação e Trabalho Docente (Difort). E-mail: claudionunesba@hotmail. com 
national teaching reality, the purpose is to reflect on the conditions of teaching in an entity within less a decade of existence in our country. As methodological guidance, it was used a descriptive research with documental and bibliographical procedure, which enabled us to achieve the proposed objective. Concerning the systematization of gathered information, it was demonstrated that the teachers at IFs are encouraged to qualification (Masters and PhD), have labs, infrastructure for researches and extension programs, and flexible hourly schedules that allow them to plan their classes and have a quiet personal life, which does not happen with teachers of municipal and state public schools.

Keywords: Teaching Career. Teacher Training.Federal Institutes, Working Conditions

\section{Carrera docente en los Institutos Federales comparándoselos con otras escuelas públicas}

\section{RESUMEN}

La investigación tiene como objeto de estudio el trabajo y el plan de carrera de los docentes de los Institutos Federales en Brasil (IFs). A partir del análisis comparativo con la realidad docente nacional, se pretende reflexionar sobre las condiciones del trabajo docente en una entidad con menos de una década de existencia en el país. Como orientación metodológica, se realizó una investigación descriptiva de carácter documental y bibliográfico, permitiendo alcanzar el objetivo propuesto. En la sistematización de las informaciones constatadas, ha sido demostrado que los docentes de los IFs son estimulados a la calificación (maestría y doctorado), disponen de laboratorios, de estructuras para investigación y extensión, de cargas horarias de trabajo flexibles que les permiten preparar sus clases y tener la vida personal tranquila, distinto de los profesores de las redes públicas municipales y estatales.

Palabras-clave: Carrera Docente. Formación Docente. Institutos Federales. Condiciones de Trabajo.

\section{Introdução}

Desde a última década é percebida no Brasil a ampliação da oferta de ensino técnico e superior. Destacam-se nesse contexto os Insti- 
tutos Federais de Educação, Ciência e Tecnologia que hoje se encontram em todo território brasileiro, oferecendo desde ensino médio técnico, passando por cursos superiores (bacharelados, licenciaturas e tecnólogos) chegando a programas de pós-graduação.

Regulamentados pela Lei no. 11.892/2008 os Institutos Federais têm sua forma de gestão equivalente ao de uma universidade federal, pois eles possuem autonomia financeira e patrimonial, atuam no tripé ensino, pesquisa e extensão com liberdade didática e pedagógica.

Diante do advento da expansão e realidade dos Institutos Federais, temos através destas entidades um enorme campo de exploração para pesquisas. Dentro destas possibilidades, podemos explorar e refletir sobre a realidade profissional dos docentes inseridos neste processo, já que a carreira federal de ensino é bastante procurada por professores de diversas áreas.

Como dito anteriormente, o Instituto Federal se caracteriza por oferecer ensino para pós-graduação, graduação (bacharelado, licenciatura e tecnólogos), técnico integrado ao médio e técnico subsequente (pós-médio). Tais entidades têm em seu corpo docente profissionais que trabalham com alunos de ensino fundamental chegando a pós-graduação. $\mathrm{O}$ que deixam os profissionais com características bastante peculiares e diferentes em relação aos docentes de outras entidades.

Partindo das peculiaridades dos docentes do Instituto Federal, o trabalho problematiza através da pesquisa bibliográfica e descritiva a realidade dos docentes e como se dão a carreira e o trabalho desses profissionais.

O artigo objetiva descrever o trabalho, plano de carreira e as características dos professores dos Institutos Federais. Pretendendo especificamente:

- Estimular os estudos sobre os Institutos federais, já que são entidades com menos de uma década de existência;

- Analisar a situação profissional dos docentes dos IF's, principalmente aqueles que trabalham com ensino médio, em comparação com a realidade nacional.

\section{Noções gerais sobre a profissão docente}

Para entender o trabalho e a profissão docente é fundamental compreender o contexto principal em que este professor está inserido, este contexto é a educação. 
Para Gatti (2008, p. 91) a educação - enquanto pensamento, ato e trabalho - está imersa na cultura, em estilos de vida, e não se acha apenas vinculada às ciências. A educação formal coloca-se, com seu modo de existir no social, em ambientes escolares e similares, organizada em torno de processos de construção e utilização dos significados que conectam o homem com a cultura onde se insere, e com suas imagens, com significados não só gerais, mas, locais e particulares, ou seja, com significados que se fazem públicos e compartilhados, mas, cujo sentido se cria nas relações que mediam seu modo de estar nos ambientes e com as pessoas que aí estão.

É necessário também entender o conhecimento profissional, este conhecimento é aquele que de forma ampla e genérica determina os vários saberes que possibilitam a um sujeito ser capaz de desempenhar funções específicas.

Freire (1996) a educação, o conhecimento profissional do professor é um conjunto de saberes teóricos e experienciais, que se expressam em um saber agir conforme a situação e em conformidade com o contexto do indivíduo. Nóvoa (2000) ressalta que de forma geral, as literaturas sobre profissão docente realçam essencialmente a dimensão técnica da ação pedagógica.

Oliveira, J. F. (2010) apresenta de forma sucinta a diversidade da profissão docente, no Brasil temos professores federais, estaduais e municipais; professores concursados e não concursados; professores urbanos e rurais; professores das redes públicas e particulares e das redes patronais profissionais (Sistema S); e professores titulados e sem titulação. Essa situação origina planos de carreira distintos (ou ausência de planos), salários diferenciados e duplicação de jornada em carreiras diferentes: estadual/municipal; pública/privada; educação básica/educação superior.

O profissional da educação, especificamente o professor, deve ser crítico e atento à realidade especifica da escola ao qual está inserido, assim, Masetto (2003) enfatiza que o professor deve ser ativo e comprometido com esta realidade.

Fortalecendo as citações acima, Nunes e Oliveira (2016) chamam a atenção para a necessidade de o professor desenvolver competência social em que este se sinta capaz de assumir as situações conflituosas provenientes das mudanças sociais de cada tempo histórico.

Arantes e Gebran (2013) acreditam que a atuação docente demanda mais do que apenas domínio de conhecimentos a serem transmitidos por um professor, exige competências próprias da docência: 
Essas competências incluem concepções de ensino, de aprendizagem, de avaliação, de formação, bem como redimensionam constantemente o aprofundamento em todas elas, envolvendo o docente em um processo de formação permanente que perpassa por toda sua formação profissional continuando na sua prática docente. (ARANTES; GEBRAN, 2013, p. 119)

Para Nunes e Oliveira (2016) a qualificação do docente faz com que ele não perca o estímulo e o entusiasmo pela profissão. $O$ profissional que não busca a qualificação terá muita dificuldade de adaptação e sobrevivência nesta educação contemporânea. Pimenta e Lima fazem a seguinte observação:

Nem sempre os professores têm clareza dos objetivos que orientam suas ações no contexto escolar e no meio onde se inserem, sobre os meios existentes para realizá-los, sobre os caminhos e procedimentos a seguir, ou seja, sobre os saberes de referência de sua ação pedagógica. (PIMENTA; LIMA 2004, p.43).

Esteve (2009) apud Nunes e Oliveira (2016, p.3) apresenta no quadro 1 os dez indicadores básicos para resumir as principais mudanças da educação nos últimos anos.

Quadro 1: Indicadores de mudança da educação (continua)

\begin{tabular}{|c|c|}
\hline Indicador & Descrição \\
\hline $\begin{array}{c}\text { Novas responsabilida- } \\
\text { des para o professor }\end{array}$ & $\begin{array}{c}\text { O professor tem de ser facilitador da aprendiza- } \\
\text { gem, organizador do trabalho, além de ter de } \\
\text { atender ao ensino, cuidar do equilíbrio psico- } \\
\text { lógico e afetivo de seus alunos, da integração } \\
\text { social etc. }\end{array}$ \\
\hline $\begin{array}{c}\text { Abandonar respon- } \\
\text { sabilidades fora da } \\
\text { escola. }\end{array}$ & $\begin{array}{c}\text { O Professor assumiu responsabilidades de outros } \\
\text { agentes sociais, como a família do aluno. }\end{array}$ \\
\hline $\begin{array}{c}\text { Compreensão pelo } \\
\text { professor da inter- } \\
\text { net e dos meios de } \\
\text { comunicação como } \\
\text { fontes de informação } \\
\text { alternativas }\end{array}$ & $\begin{array}{c}\text { Não se pode esquecer que muitos estudantes } \\
\text { acompanham os avanços das tecnologias da } \\
\text { comunicação e da informação com muito mais } \\
\text { propriedade do que o fazem alguns } \\
\text { professores. }\end{array}$ \\
\hline \multicolumn{2}{|c|}{} \\
\hline
\end{tabular}


Quadro 1: Indicadores de mudança da educação

(continuação)

\begin{tabular}{|c|c|}
\hline Indicador & Descrição \\
\hline $\begin{array}{l}\text { Diferentes modelos } \\
\text { educativos na socie- } \\
\text { dade plural }\end{array}$ & $\begin{array}{l}\text { O professor precisa incorporar em suas aulas uma } \\
\text { postura sensível a questões de natureza linguísti- } \\
\text { ca e cultural muito diversas, posto que os alunos } \\
\text { provêm de contextos sociais com educação fami- } \\
\text { liar em que os valores são igualmente distintos. }\end{array}$ \\
\hline $\begin{array}{l}\text { Busca de equilíbrio } \\
\text { ante os modelos } \\
\text { educativos contra- } \\
\text {-correntes. }\end{array}$ & $\begin{array}{l}\text { Observar não apenas a diversidade cultural, mas } \\
\text { também atender às determinações provenientes } \\
\text { das novas legislações que surgem em resposta } \\
\text { às demandas da própria pluriculturalidade. }\end{array}$ \\
\hline $\begin{array}{l}\text { Mudança na renta- } \\
\text { bilidade social da } \\
\text { educação. }\end{array}$ & $\begin{array}{l}\text { Professores, alunos e pais devem entender que a } \\
\text { escola pode proporcionar a formação e o desen- } \\
\text { volvimento do cidadão na sociedade contem- } \\
\text { porânea, mas não constitui o status social que } \\
\text { oferecia no passado. }\end{array}$ \\
\hline $\begin{array}{l}\text { Juízo social do profes- } \\
\text { sor e a crítica genera- } \\
\text { lizada ao sistema de } \\
\text { ensino. }\end{array}$ & $\begin{array}{l}\text { No passado, os pais e a sociedade, em geral, } \\
\text { apoiavam os professores em relação às dificulda- } \\
\text { des do processo educativo, atualmente defen- } \\
\text { dem os alunos/filhos. }\end{array}$ \\
\hline $\begin{array}{l}\text { Consideração social } \\
\text { do professor em sua } \\
\text { sociedade materialis- } \\
\text { ta como uma questão } \\
\text { ideológica. }\end{array}$ & $\begin{array}{c}\text { A posição ocupada pelo professor na sociedade } \\
\text { atual termina por absorver as representações } \\
\text { que são estabelecidas sobre este ramo profissio- } \\
\text { nal tanto por outros sujeitos sociais como pelo } \\
\text { próprio professor. }\end{array}$ \\
\hline $\begin{array}{l}\text { Necessidade de } \\
\text { revisar os conteúdos } \\
\text { curriculares }\end{array}$ & $\begin{array}{l}\text { Ao se entender que o conteúdo é um dos } \\
\text { elementos centrais na composição de uma aula, } \\
\text { espera-se que o professor esteja atualizado, te- } \\
\text { órica e metodologicamente, sobre as inovações } \\
\text { científicas por que passa o conteúdo em sua pró- } \\
\text { pria área e nas interfaces com as diferentes áreas } \\
\text { do conhecimento científico. }\end{array}$ \\
\hline $\begin{array}{l}\text { Autoridade e discipli- } \\
\text { na na relação educa- } \\
\text { tiva. }\end{array}$ & $\begin{array}{l}\text { Se no passado professor era considerado o } \\
\text { detentor de todo o poder dentro da sala de aula } \\
\text { em detrimento dos estudantes, atualmente essa } \\
\text { situação se inverteu, chegando a causar, em } \\
\text { alguns contextos escolares, muitos conflitos entre } \\
\text { professor e alunos, com agressões verbais e físicas }\end{array}$ \\
\hline
\end{tabular}

Fonte: Adaptação de ESTEVE (2009 apud NUNES; OLIVEIRA, 2016) 
Nunes e Oliveira (2016) ressaltam que sem dúvida, esses indicadores de mudança identificados por Esteve (2009) têm implicações para o trabalho, para a carreira, para o desenvolvimento profissional e para a qualidade da educação oferecida pela escola básica. Ainda que o autor tenha como referência o contexto europeu, esta realidade também pode ser observada na região latino-americana e mais especificamente no Brasil.

\section{Características do profissional docente no Brasil.}

Ilha e Hypólito (2014) ressaltam que o desenvolvimento profissional propicia uma visão mais adequada ao significado do processo de formação, no momento que transcende a justaposição formação inicial e formação continuada.

Os mesmos autores Ilha e Hypólito (2014, p. 101) trouxeram um estudo dos ciclos de vida profissional docente para identificar e analisar as regularidades vividas no decurso da carreira. Assim destacam-se as seguintes fases:

- Fase de entrada na carreira;

- Fase de Estabilização;

- Fase de diversificação;

- Fase de serenidade; e

- Fase de desinvestimento.

Para Ilha e Hypólito (2014) percebe-se, assim, que o professor ao longo da carreira passa por processos diferenciados e peculiares, que podem ser caracterizados por fases da trajetória profissional.

Para Sampaio e Marin (2004) a realidade docente pode assim ser entendida:

- professores que atuam sem habilitação, a cada ano, em disciplina diferente daquela lecionada no ano anterior;

- professores que atuam, ao mesmo tempo, em disciplinas de áreas diferentes;

- professores que não constam mais das relações da Secretaria da Educação como não habilitados, mas classificados como PEB I, ou seja, similares a professores primários; um artifício administrativo para ocultar tal situação.

Outra questão bem peculiar da realidade do docente no Brasil são os baixos salários, é o que mostra a seguinte citação: 
Das questões bem visíveis da precarização do trabaIho do professor refere-se ao salário recebido pelo tempo de dedicação às suas funções, sobretudo quando se focaliza a imensa maioria, ou seja, os que atuam nas diversas escolas da rede pública. (SAMPAIO; MARIN 2004, p. 1210)

Segundo os mesmos autores, dados de 1997 informam-nos que o cálculo bruto da média salarial de docentes da educação básica brasileira era de $\mathrm{R} \$ 529,92$, numa escala que variava de $\mathrm{R} \$ 221,22$ (na Paraíba) a R\$ 1.364,30 (no Distrito Federal). A grande maioria tem renda familiar entre 2 (dois) e 10 (dez) salários mínimos.

Sobre a qualificação dos docentes no Brasil Sampaio e Marin (2004) trazem dados de uma pesquisa da UNESCO, esta ressalta a seguinte informação:

\begin{abstract}
O processo de realimentação quanto a informações, em geral, fica restrito à frequência a cursos de especialização, que muitos deles apontaram, ou estar sintonizado com o mundo é uma possibilidade que ocorre por meio da televisão, quando há tempo. (SAMPAIO; MARIN 2004, p. 1211)
\end{abstract}

Sampaio e Marin (2004) ressaltam as faces que caracterizam as condições de trabalho no Brasil. Merecem destaque: carga horária de trabalho e de ensino, tamanho das turmas e razão entre professor/alunos, rotatividade/itinerância dos professores pelas escolas e as questões sobre carreira no magistério. $\mathrm{O}$ quadro 2 apresenta resumidamente cada uma destas faces e suas características.

Para Oliveira (2009, p. 366) "o processo de intensificação na docência brasileira provoca a degradação do trabalho não só em termos de qualidade da atividade, mas também da qualidade do bem ou do serviço produzido".

\title{
Aspectos metodológicos
}

O presente trabalho se caracteriza como descritivo, pois busca fazer uma conexão entre a realidade e a literatura. Gil (1991, p.46), explicita que "as pesquisas descritivas têm como objetivo primordial a descrição das características de determinada população ou fenômeno ou, então, o estabelecimento de relações entre variáveis". Vergara (2010) 
complementa afirmando que neste tipo de pesquisa não existe o comprometimento de prestar explicações dos fatos descritos.

Quadro 2: Caracterização das condições de trabalho docente no Brasil

\begin{tabular}{|c|c|}
\hline $\begin{array}{c}\text { Condições de } \\
\text { trabalho }\end{array}$ & Características \\
\hline $\begin{array}{c}\text { Carga horária } \\
\text { de trabalho/ } \\
\text { de ensino }\end{array}$ & $\begin{array}{l}\text { - As horas-atividade de grande parte dos professores são } \\
\text { utilizadas individualmente e fora do ambiente escolar, } \\
\text { portanto, sem a garantia de que de fato constituam tem- } \\
\text { po de estudo para atualização; } \\
\text { - Nas séries de } 5^{a} \text { a } 8^{a} \text { não é obrigatória a atribuição de tal } \\
\text { carga de trabalho, fato que estabelece disparidade de } \\
\text { condição de trabalho entre os professores de uma mesma } \\
\text { escola; } \\
\text { - Não existe a dedicação exclusiva: Os professores das sé- } \\
\text { ries iniciais, em alguns locais, ainda dobram a jornada } \\
\text { assumindo carga horária em escolas de redes públicas di- } \\
\text { ferentes - estadual e municipal - ou em escolas públicas } \\
\text { e privadas. }\end{array}$ \\
\hline $\begin{array}{l}\text { Tamanho das } \\
\text { turmas }\end{array}$ & $\begin{array}{l}\text { - Dados de } 2001 \text { divulgados pelo Instituto Nacional de Estu- } \\
\text { dos e Pesquisas Educacionais (INEP), ligado ao MEC (Brasil, } \\
\text { 2002), revelam que o número médio de alunos por turma } \\
\text { era de } 28,3 \text {, numa escala que variava de } 22,2 \text { em Roraima } \\
\text { a } 32,9 \text { em Alagoas, no ensino fundamental regular, e } 37,6 \\
\text { no Brasil variando de 30,9 em Roraima a 43,0 em Sergipe. }\end{array}$ \\
\hline $\begin{array}{l}\text { Razão profes- } \\
\text { sor/alunos }\end{array}$ & $\begin{array}{l}\text { - No Brasil, a razão entre professores e alunos no ano de } \\
1999 \text { foi de: educação primária (ensino fundamental) - } \\
\text { 28,9; educação secundária - séries iniciais (ensino funda- } \\
\text { mental) - 33,7; educação secundária - séries finais (ensino } \\
\text { médio) - 38,4; } \\
\text { - Estes números estão bem acima, por exemplo, da média } \\
\text { obtida pelos países da OCDE, em que a razão é de } 17 \text { para } \\
\text { a educação primária, } 15 \text { para as séries iniciais do secundá- } \\
\text { rio e } 14 \text { para as séries finais do secundário. }\end{array}$ \\
\hline $\begin{array}{l}\text { Rotatividade/ } \\
\text { itinerância }\end{array}$ & $\begin{array}{l}\text { - Rotatividade de professores nas escolas, de um ano para } \\
\text { outro ou, às vezes, num mesmo ano, e da itinerância de- } \\
\text { les por várias escolas, ao mesmo tempo, ao longo do ano, }\end{array}$ \\
\hline
\end{tabular}

Fonte: Adaptação de Sampaio e Marin (2004).

Para Gil (1991) o caráter exploratório assegura que este tipo de metodologia permite criar maior familiaridade com o problema. 
Quantos aos procedimentos técnicos, a pesquisa é caracterizada como documental e bibliográfica. Gil (1991) comenta que essa abordagem se assemelha com a bibliográfica, sendo a fonte de dados a principal diferença.

\section{Resultado - O perfil dos professores do IF}

Os Institutos Federais foram criados através da Lei no. 11.892, de 29 de dezembro de 2008. Tais entidades são consideradas impares na educação brasileira, já que têm uma estrutura parecida às das universidades, mas que, além do ensino superior e da pós-graduação, oferecem ensino médio e técnico também, o que possibilita ao professor trabalhar em diversas funções que vão desde a formação do técnico à possibilidade de formação de um doutor, em um prisma denominado verticalização do ensino.

A Lei no. 11.892, de 29 de dezembro de 2008 (BRASIL, 2008), veio institucionalizar oficialmente a rede no âmbito do sistema federal de ensino como Rede Federal de Educação Profissional, Científica e Tecnológica, com vinculação ao Ministério da Educação, sendo composta por 38 Institutos Federais de Educação, Ciência e Tecnologia - Institutos Federais, pela Universidade Tecnológica Federal do Paraná, pelos Centros Federais de Educação Tecnológica Celso Suckow da Fonseca e de Minas Gerais e por 24 Escolas Técnicas Vinculadas a Universidades Federais.

Ainda a mesma Lei $n^{\circ}$. 11.892/08, em seu artigo $6^{\circ}$, definiu os Institutos Federais como uma Instituição de Ensino com a finalidade de ofertar educação profissional e tecnológica em todos os níveis e modalidades e promover a integração e a verticalização da educação profissional, desde a educação básica até a educação superior, otimizando a infraestrutura física, os quadros de pessoal e os recursos de gestão.

A presente lei ainda estabelece em seu texto que o Instituto Federal deve se constituir como centro de excelência na oferta do ensino de ciências, em geral, e de ciências aplicadas, em particular, e qualificar-se como referência no apoio à oferta do ensino de ciências nas instituições públicas de ensino, oferecendo capacitação técnica e atualização aos docentes.

Segundo o MEC (2016) os Institutos Federais cobrem todo o território nacional, contribuindo para a qualificação de profissionais para diversos setores da economia brasileira, produzindo pesquisa e serviços 
no fomento do setor produtivo. São 644 unidades espalhadas por todo Brasil.

A Lei $n^{\circ} .12 .772$, de 28 de dezembro de 2012, que regulamenta o plano de carreira e cargos de magistério do ensino básico, técnico e tecnológico e sobre o plano de carreira de magistério do ensino básico federal, define os parâmetros profissionais da carreira do professor dos Institutos Federais. Como todo servidor público, o professor do IF passa por um concurso público para ingressar no nível 1 da classe $D I$.

De acordo com a mesma lei, a carreira de magistério do ensino básico, técnico e tecnológico (dos professores do Instituto Federal) é composta das seguintes classes, alcançadas pelos respectivos marcos:

- I - D de defesa de tese acadêmica inédita. I: ser aprovado em concurso público;

- II - D II: ser aprovado em processo de avaliação de desempenho, de acordo com diretrizes estabelecidas pelo Ministério da Educação e normatizada pelo Colegiado Superior das IFE;

- III - D III: ser aprovado em processo de avaliação de desempenho, de acordo com diretrizes estabelecidas pelo Ministério da Educação e normatizada pelo Colegiado Superior das IFE;

- IV - D IV: ser aprovado em processo de avaliação de desempenho, de acordo com diretrizes estabelecidas pelo MEC e critérios aprovados pelo Conselho Superior da IFE e possuir o título de Doutor ou Mestre;

- V - Titular: ser aprovado em processo de avaliação de desempenho, de acordo com diretrizes estabelecidas em regulamento. Lograr aprovação de Memorial que deverá considerar as atividades de ensino, pesquisa, extensão, gestão acadêmica e produção profissional relevante, ou

Observação: Além dos requisitos apresentados para promoção de uma categoria para outra, é importante registrar que existe, ainda, a categoria de aceleração da promoção após estágio probatório:

- Promoção por Titulação: DI para DII pela obtenção do título de Especialista e DII para DIII pela obtenção do título de Mestre ou Doutor.

Os professores dos Institutos Federais ainda contam com a concessão do Reconhecimento de Saberes e Competências (RSC). O RSC, para fins da Retribuição por Titulação (RT), é um processo pelo qual são reconhecidos os conhecimentos e habilidades desenvolvidos a partir da experiência individual e profissional, bem como no exercício das ati- 
vidades realizadas no âmbito acadêmico, conforme disposto na Lei nº $12.772 / 2012$.

O RSC é validado pela Lei no. 12.772 em seu artigo 18:

No caso dos ocupantes de cargos da Carreira de Magistério do Ensino Básico, Técnico e Tecnológico, para fins de percepção da RT, será considerada a equivalência da titulação exigida com o Reconhecimento de Saberes e Competências - RSC. (BRASIL 2012).

O RSC permite ao professor do Instituto Federal pleitear a RT de uma categoria acima, sem ainda ter de fato esse título. Por exemplo, um especialista pode entrar com a documentação e pedir a equivalência da RT de um Mestre, um Mestre pode pleitear a equivalência de uma RT de Doutor.

Atualmente existem três categorias em que o professor pode pedir o seu RSC, ou seja, o RSC I ao qual o profissional com apenas Graduação recebe salários equivalente ao de um Especialista, o RSC II na qual o Especialista recebe como Mestre e o RSC III na qual o Mestre recebe como Doutor.

A Lei 12.772/2012 prevê que o docente só poderá obter o RSC referente ao título imediatamente acima daquele que possui, por exemplo, um Especialista só pode pedir o RSC II (equivalente a mestre) e não a RSC III (equivalente a doutor) para pedir o RSC III é necessário que o mesmo tenha mestrado. Cada instituição (cada Instituto Federal) deverá ter um regulamento interno aprovado pelo Conselho Superior ou instância equivalente com procedimentos, solicitação e processo de avaliação de acordo com as diretrizes gerais do RSC.

O professor deverá escrever o relatório descritivo ou memorial de forma cronológica; preencher o formulário ou a planilha com as atividades declaradas, devidamente comprovadas e anexadas ao processo; preencher um barema que comprove a sua pontuação mínima para o RSC que desejar, preencher um requerimento; imprimir, assinar e enviar com todos os documentos "escaneados" e impressos à Comissão Permanente do Pessoal Docente (CPPD), através da sua unidade ou campus de lotação.

O IFEs que não têm CPPD (caso das IFEs militares) ou em que essas não sejam formadas exclusivamente por professores do ensino básico, técnico e tecnológico (EBTT) (caso de muitas universidades) devem 
atender ao $\S 2^{\circ}$ da Resolução 1 do CPRSC que determina que "será criada uma comissão análoga à CPPD, por membros eleitos por seus pares".

Todo este processo é encaminhado para uma banca com três professores da Rede Federal, cadastrados no Sistema Integrado de Monitoramento Execução e Controle (SIMEC), sendo dois professores externos (de Institutos Federais diferentes ao do candidato que está em avaliação) e um professor interno (mesmo IF do candidato em avaliação). Dos três avaliadores, dois aprovando o processo, o candidato está apto a receber o RSC, caso contrário, ou seja, não sendo aprovado, o candidato só poderá submeter novamente o processo após seis meses.

Em relação ao modo de contratação dos professores dos IF's, de acordo com a Lei no. 12.772/2012, os professores efetivos dos Institutos Federais devem ser contratados (através de concurso) pelos seguintes regimes: 20 horas semanais (sem dedicação exclusiva), 40 horas semanais (sem dedicação exclusiva) e Dedicação exclusiva com 40 horas semanais. A tabela 1 apresenta a remuneração destes profissionais:

De acordo com IFNMG Campus Almenara (2015) a carga de trabalho para os docentes segue a seguinte distribuição:

- Categoria 40 horas e Dedicação Exclusiva: 16 horas aulas semanais;

- Categoria 20 horas: 8 horas aulas semanais

De acordo com a Direção de ensino deste mesmo campus esta divisão permite ao professor além das aulas, trabalhar na preparação das mesmas, elaborar e participar de projetos de extensão e pesquisa e, principalmente, desenvolver-se profissionalmente.

O desenvolvimento profissional é fundamental em qualquer carreira, na docência esse desenvolvimento é por vezes comprometido pelas diversas atribuições do professor. Na prática podemos entender a importância do desenvolvimento profissional docente pela seguinte citação:

Desenvolver-se profissionalmente significa articular vida pessoal e profissional; significa viver a profissão. O desenvolvimento profissional não se inicia quando entramos na carreira docente, tem início antes, pois as experiências pessoais anteriores à carreira funcionam como dispositivos formativos para o desenvolvimento profissional docente; nós utilizamos as experiências anteriores para sermos os professores que somos, para nos fazermos professores (SANTOS; FERREIRA, 2016, p. 132). 


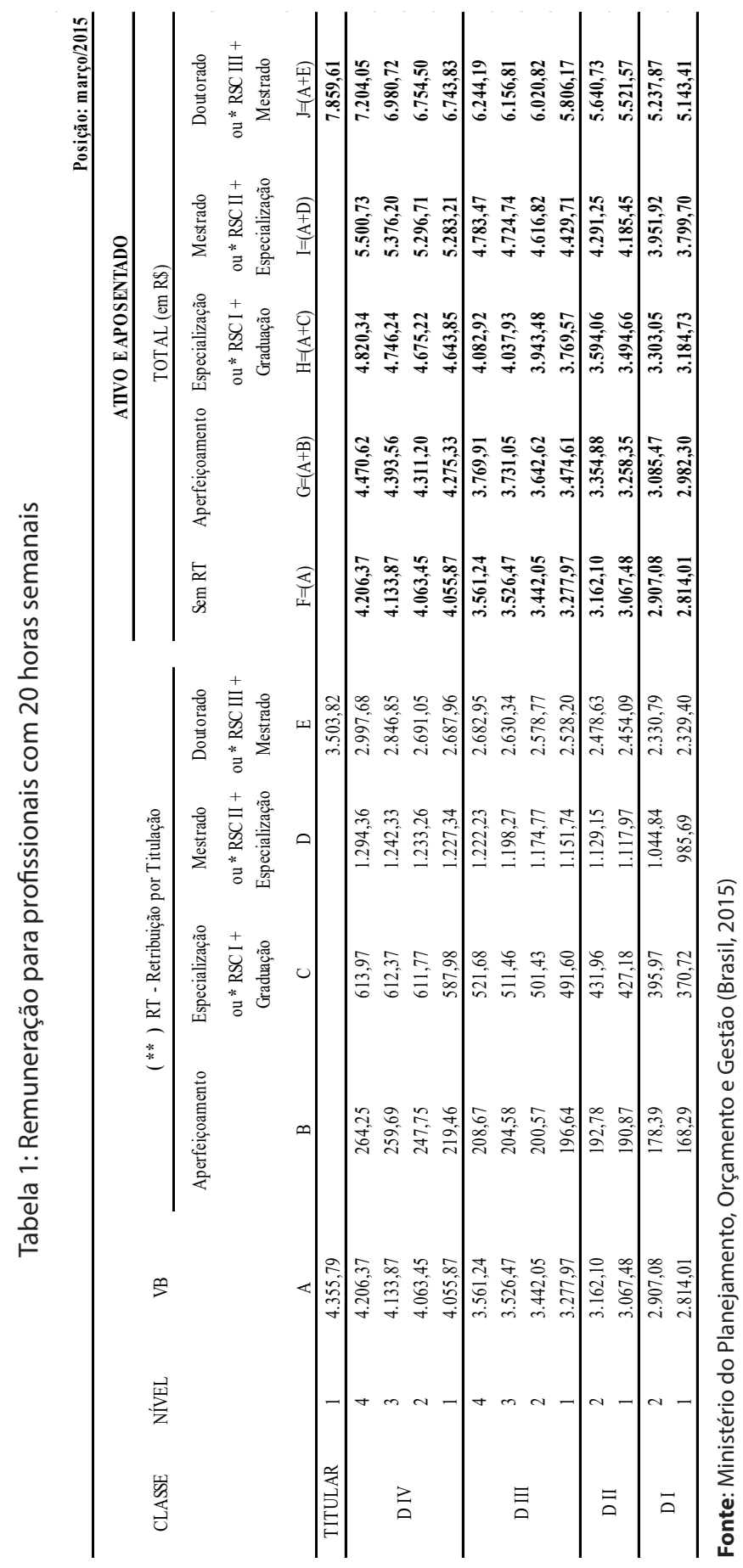




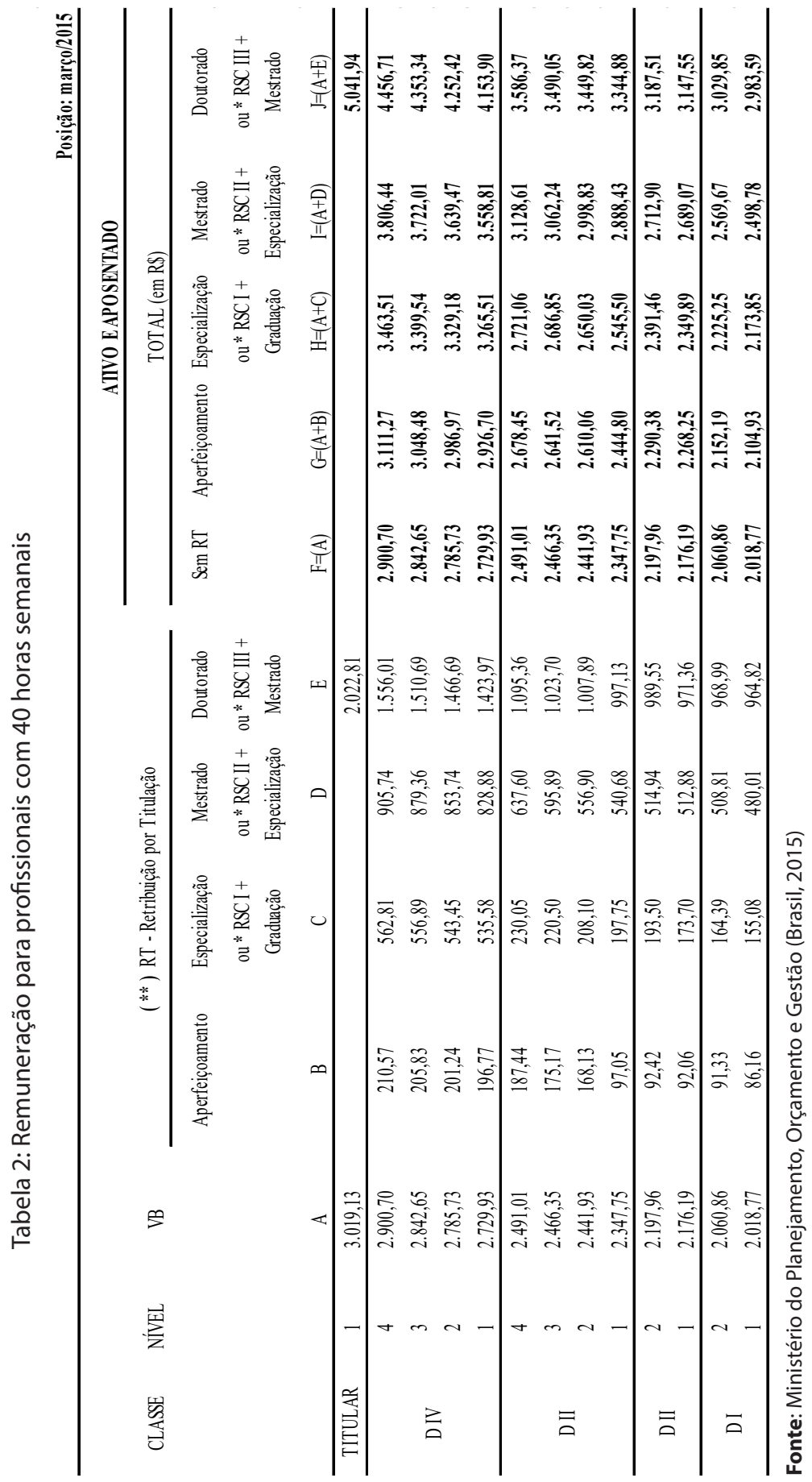




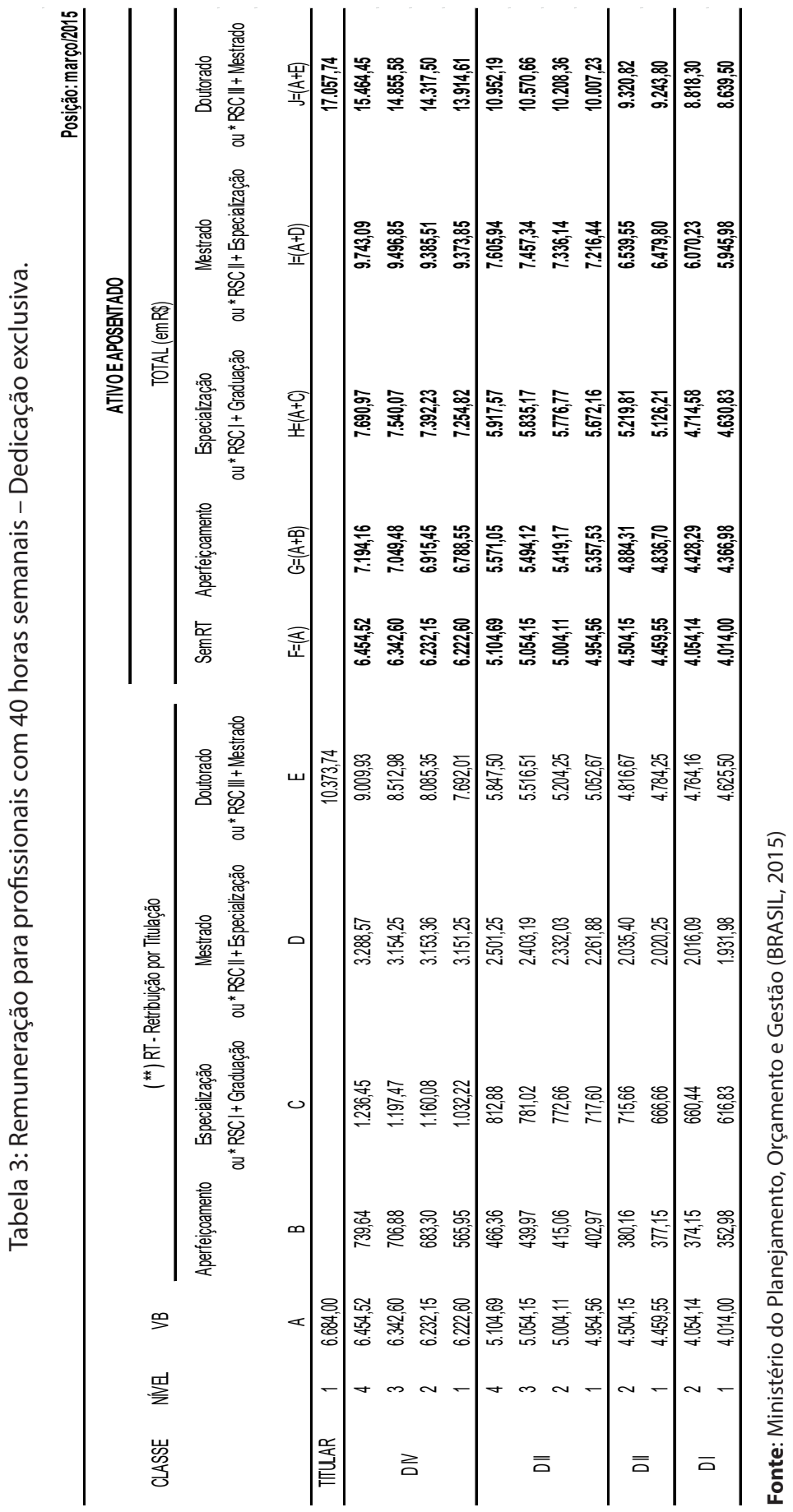


O Ministério da Educação através da Portaria no. 818, de 13 de agosto de 2015 regulamentou o conceito de aluno-equivalente, que ajudará a aperfeiçoar a atuação dos Institutos Federais de Educação, Ciência e Tecnologia, dos Centros Federais de Educação Tecnológica. Este conceito é importante para o acompanhamento dos percentuais mínimos de oferta de cursos técnicos e de formação de professores, previstos em lei, e da relação do número de alunos por professor, estabelecida no Plano Nacional de Educação (PNE).

Ainda, segundo o MEC, o aluno-equivalente é aplicado a todos os cursos, desde a qualificação profissional até a pós-graduação. São consideradas a carga horária e o grau de complexidade dos cursos, especialmente a exigência de aulas práticas com divisão de turmas.

Entre os resultados que serão influenciados pelo aluno-equivalente, destaca-se a garantia de oferta de pelo menos $50 \%$ das vagas dos Institutos Federais em cursos técnicos de nível médio e pelo menos $20 \%$ em cursos destinados a licenciaturas e formação de professores, conforme previsto na Lei no. 11.892, de 29 de dezembro de 2008.

A Portaria no. 818, de 13 de agosto de 2015 cumpre a relação aluno professor (RAP) de 20 para 1, prevista no PNE. Ou seja, para cada professor, as instituições deverão atender 20 alunos-equivalentes, entre cursos técnicos e de qualificação profissional.

O quadro 3 apresentará um comparativo da situação de trabaIho dos professores dos Institutos Federais com professores do ensino médio no Brasil:

Constatamos pela análise dos textos base e os resultados encontrados na pesquisa que existe uma diferença bastante considerável nessa comparação. A realidade do profissional docente das escolas públicas (municipais e estaduais) brasileiras ainda carece de uma boa melhoria. Através da comparação, é possível verificar que a educação pode avançar e o modelo pode ser o que se aplica nos Institutos Federais.

\section{Conclusão}

Os Institutos Federais são entidades que ainda não têm uma década de existência. Além de novos, são estruturas educacionais, completamente, diferente de outras entidades educacionais, presentes no Brasil. Eles têm a autonomia das universidades federais, mas oferecem ensino técnico, tecnológico e superior. O que nos permite dizer 
que ainda estão construindo a sua identidade enquanto instituição no Brasil.

Quadro 3: Comparativo entre os docentes dos IF's com Professores do Ensino médio (Municipal e Estadual).

\begin{tabular}{|c|c|c|}
\hline Características & $\begin{array}{c}\text { Professores dos } \\
\text { Institutos Federais }\end{array}$ & $\begin{array}{c}\text { Professores Ens. Médio } \\
\text { (Municipais e Estaduais) }\end{array}$ \\
\hline $\begin{array}{c}\text { Habilitação } \\
\text { Mínima }\end{array}$ & $\begin{array}{c}\text { Graduação (curso supe- } \\
\text { rior) }\end{array}$ & $\begin{array}{c}\text { Vários casos de profes- } \\
\text { sores sem graduação }\end{array}$ \\
\hline $\begin{array}{c}\text { Piso salarial } \\
\text { para 40 horas } \\
\text { DE (sem titula- } \\
\text { ção) }\end{array}$ & R\$ 4.014,00 & $\begin{array}{c}\text { R\$ 1.917,78 - Aprovado a } \\
\text { pouco tempo, mas ainda } \\
\text { não aplicável a maioria dos } \\
\text { professores. }\end{array}$ \\
\hline $\begin{array}{c}\text { Programas de } \\
\text { qualificação }\end{array}$ & $\begin{array}{c}\text { Estímulo à qualificação } \\
\text { (mestrado, doutorado } \\
\text { e pós-doutorado) com } \\
\text { financiamento e afasta- } \\
\text { mento da função. }\end{array}$ & $\begin{array}{c}\text { Restrito a especialização } \\
\text { de acordo com o estímulo } \\
\text { pessoal. }\end{array}$ \\
\hline $\begin{array}{c}\text { Carga Horária } \\
\text { Máxima de 40 horas, } \\
\text { distribuídas em ensino, } \\
\text { pesquisa e extensão. }\end{array}$ & $\begin{array}{c}\text { Limite máximo não esti- } \\
\text { pulado, já que não existe a } \\
\text { dedicação exclusiva. }\end{array}$ \\
\hline $\begin{array}{c}\text { Relação aluno } \\
\text { por professor }\end{array}$ & $\begin{array}{c}20 \text { alunos para cada } \\
\text { docente }\end{array}$ & $\begin{array}{c}\text { Podendo chegar a 43 alu- } \\
\text { nos por docente. }\end{array}$ \\
\hline $\begin{array}{c}\text { Plano de Car- } \\
\text { reira }\end{array}$ & $\begin{array}{c}\text { Definido - O Professor } \\
\text { já entra na instituição já } \\
\text { sabendo a remuneração } \\
\text { da carreira. }\end{array}$ & $\begin{array}{c}\text { Variável de acordo cada } \\
\text { estado ou município. }\end{array}$ \\
\hline
\end{tabular}

Fonte: Elaborada pelo autor

Os professores dos IF's podem aqui ser chamados de híbridos já que um mesmo profissional pode lecionar no ensino médio de primeiro ano, como em uma pós-graduação scrito sensu. Estes profissionais são estimulados a qualificação (mestrado e doutorado), dispõem de laboratórios, estruturas para pesquisa e extensão, cargas horárias de trabalhos flexíveis que permitem a eles prepararem suas aulas e terem vida pessoal tranquila.

Este estudo objetivou comparar os professores dos Institutos Federais, aqueles que trabalham no ensino médio, com os professores 
do ensino médio das escolas públicas brasileiras (municipais e estaduais).

Finalizando, chamamos a atenção de que este trabalho não pode ser tomado como uma análise da realidade crua de parte da educação no Brasil, muito longe disso. O tema carece de avanço na pesquisa, a sua efetiva contribuição foi nos permitir refletir sobre a realidade docente de uma instituição ainda nos anos iniciais com boas possibilidades de oferecer um trabalho mais digno aos professores.

\section{Referências}

ARANTES, Ana Paula Pereira; GEBRAN, Raimunda Abou. Professores do ensino superior: trajetórias e saberes. Revista Educação e Emancipação, São Luís, v. 6, p. 93-126-126, 2013.

BRASIL. Lei no. 11.892, de 29 de dezembro de 2008. Institui a Rede Federal de Educação Profissional, Científica e Tecnológica, cria os Institutos Federais de Educação, Ciência e Tecnologia, e dá outras providências. Diário Oficial da União, Seção 1, p. 1, 30/12/2008.

, Lei no.12.772/2012 de 28 de dezembro de 2012. Dispõe sobre a estruturação do Plano de Carreiras e Cargos de Magistério Federal; sobre a Carreira do Magistério Superior, de que trata a Lei no 7.596, de 10 de abril de 1987; sobre o Plano de Carreira e Cargos de Magistério do Ensino Básico, Técnico e Tecnológico e sobre o Plano de Carreiras de Magistério do Ensino Básico Federal. Diário Ofcial [da] República Federativa do Brasil, Brasília, DF, 21 dez. 2012.

,MINISTÉRIODAEDUCAÇÃO.SecretariadeEducaçãoProfissional

e Tecnológica (SETEC). Disponível em: <http://portal.mec.gov.br/index. php?option=com_content $\&$ view $=$ article\&id $=14945 \&$ ltemid $=1064>$. Acesso em 26 jan. 2016.

GATTI, B. A. Formação de professores: condições e problemas atuais. Chagas/Fundação Vitor Civita, São Paulo, 2008, v.1 e 2 (impresso e disponível site: www.fcc.org.br)

FREIRE, P. Pedagogia da autonomia: saberes necessários à prática educativa, 34. ed. São Paulo: Paz e Terra, 1996.

GIL, Antônio Carlos. Como elaborar projeto de pesquisa. 3. ed. São Paulo: Atlas, 1991. 
IFNMG. Departamento de Ensino. Programa de Qualificação IFNMG Almenara. 2015.

ILHA, F.R.S; HYPOLITO, A.M. O trabalho docente no início da carreira e sua contribuição para o desenvolvimento profissional do professor. Práxis Educacional Vitória da Conquista v. 10, n. 17, p. 99-114, jul./dez. 2014 NÓVOA, A. Os professores e a história da sua vida. In: NÓVOA, A. (Org.). Vida de professores. 2. ed. Porto: Porto Editora, 2000.

NUNES, C. P.; OLIVEIRA, D. A. Trabalho, carreira, desenvolvimento docente e mudança na prática educativa. Educação e Pesquisa, São Paulo, 2016. OLIVEIRA, D. A. Os trabalhadores da educação e a construção política da profissão docente no Brasil. Educar em Revista, Curitiba, n. especial 1, p. 17-35, 2010.

OLIVEIRA, João Ferreira de. A articulação entre universidade e educação básica na formação inicial e continuada de professores: demandas contemporâneas, situação-problema e desafios atuais. In: LEIRO, Augusto César Rios; SOUZA, Elizeu Clementino de (orgs.). Educação básica e trabalho docente: políticas e práticas de formação. Salvador: EDUFBA, 2010.

PIMENTA, Selma Garrido; LIMA. Maria Socorro Lucena. Estágio e docência. São Paulo: Cortez, 2004.

SAMPAIO, M. M. F; MARIN, A. J. Precarização do trabalho docente e seus efeitos sobre as práticas curriculares. Educação e Sociedade, Campinas, v. 25, n. 89, p. 1203-1225, set./dez. 2004.

SANTOS, J. R e FERREIRA, L. G. Desenvolvimento Profissional, Vida e Carreira: História de professores atingidos pelo mal-estar docente. Revista Educação e Emancipação, São Luís, v. 9, n. 2, jul./dez. 2016.

VERGARA, Sylvia C. Metodologia Reflexiva. In: VERGARA, S.C. Métodos de pesquisa em Administração. 4 ed. São Paulo: Atlas, 2010, p.172-181.

Recebido em outubro/2016

Aceito em fevereiro/2017 